\title{
In vitro methods for antifungal susceptibility testing of Trichophyton spp.
}

\section{Maria Elisabete da Silva BARROS*, Daniel de Assis SANTOS, Júnia Soares HAMDAN}

Department of Microbiology, Institute of Biological Sciences, Federal University of Minas Gerais, Av. Antônio Carlos, 6627 PO Box 486 CEP: 31.270-901, Belo Horizonte, Minas Gerais, Brazil

\section{A R T I C L E I N F O}

Article history:

Received 8 November 2005

Received in revised form

14 July 2006

Accepted 12 August 2006

Published online 25 October 2006

Corresponding Editor:

Mark Ramsdale

Keywords:

Antifungal drugs

Dermatophytes

Microdilution

Susceptibility testing

\begin{abstract}
A B S T R A C T
In general, methods to test the susceptibility of fungi to antifungal drugs require standardized techniques, but so far there is no methodology that is widely applicable to dermatophytes. Here we introduced modifications to the protocols from documents of the National Committee for Clinical Laboratory Standards (CLSI) M38-A and the Antifungal Susceptibility Testing Subcommittee of the European Committee on Antimicrobial Susceptibility Testing (EUCAST) that are usually applied to moulds and fermentative yeasts, in order to adjust the conditions for the growth of dermatophytes. The modifications included: growth on potato dextrose agar supplemented with $2 \%$ in-house rice flour to encourage sporulation, the addition of $2 \%$ glucose to the culture media (RPMI-1640), and an incubation temperature of $28{ }^{\circ} \mathrm{C}$. In addition, the incubation period was $7 \mathrm{~d}$, the minimum inhibitory concentration (MIC) was defined as $80 \%$ growth inhibition endpoints for azole agents, and the inocula only contained microconidia. Results obtained by both tested methodologies were very similar to the ones reported by other researchers. MIC 90 (MIC at which $90 \%$ of isolates tested were inhibited) values were identical for four out of five antifungal drugs tested and there was only a difference of one or two dilutions when $\mathrm{MIC}_{50}$ values were compared. Although the modifications introduced did not interfere with the results, more studies are necessary to establish a standard technique to test susceptibility of dermatophytes to antifungal drugs.

๑ 2006 The British Mycological Society. Published by Elsevier Ltd. All rights reserved.
\end{abstract}

\section{Introduction}

The approval of protocols M27-A2 (CLSI 2002a) and M38-A (CLSI 2002b), by the National Committee for Clinical Laboratory Standards (CLSI), motivated research on new methods for the standardization of susceptibility tests for yeasts and filamentous fungi. As an example, Meletiadis et al. (2002) have developed colorimetric and diffusion in agar methods. Protocol M27-A2 is specific for the determination of minimum inhibitory concentrations (MICs) for yeasts (Cryptococcus neoformans and Candida spp.), and protocol M38-A for filamentous, sporangiospore and conidium-forming fungi that cause invasive mycoses. Both protocols use the culture medium RPMI-1640 (without sodium bicarbonate and L-glutamine at $\mathrm{pH}$ 7.0) supplemented with $0.165 \mathrm{~m}$ morpholinepropanesulphonic acid (MOPS) and an incubation temperature of $35^{\circ} \mathrm{C}$. Inocula are $10^{4} \mathrm{CFU} \mathrm{ml} \mathrm{m}^{-1}$ for Cryptococcus neoformans and $10^{3} \mathrm{CFU} \mathrm{ml} \mathrm{m}^{-1}$ for Candida spp. The incubation period is of 24-48 h (document M27-A2) or up to $4 \mathrm{~d}$ (document M38-A). Visual readings are performed in both cases. The protocol of the Antifungal Susceptibility Testing Subcommittee of the European Committee on Antimicrobial Susceptibility Testing (AFST-EUCAST; approved in 2002) is used to determine MIC values for fermentative yeasts. This document recommends

\footnotetext{
* Corresponding author.

E-mail address: betebarros@ef.ufop.br 0953-7562/\$ - see front matter @ 2006 The British Mycological Society. Published by Elsevier Ltd. All rights reserved. doi:10.1016/j.mycres.2006.08.006
} 
the use of RPMI-1640 supplemented with $2 \%$ glucose at $\mathrm{pH} 7.0$ (buffered with MOPS $0.165 \mathrm{M}$ ), a temperature of $35^{\circ} \mathrm{C}$, an incubation period of $48 \mathrm{~h}$, inocula of $10^{5} \mathrm{CFU} \mathrm{ml}^{-1}$ and spectophotometric readings. Whilst these methods are reproducible (Cuenca-Estrella et al. 2002, 2003), so far there are no methods to determine the MIC values of dermatophyte fungi that cause infections of the skin, hair and nail in humans and animals. Among these infections, onychomycosis are the most difficult to treat, affecting $20 \%$ of the world population under 40 -years old (Bradley et al. 1999). These infections affect the nail bed causing dystrophy and sometimes result in complete nail loss (Roberts et al. 2003). Although there are many antifungal drugs available that can be taken orally, only terbinafine, itraconazole and fluconazole are effective in the treatment of onychomycosis. Several topical antifungal preparations like amorolfine and tioconazole are available as nail lacquer or solution form. These topical antifungal drugs can be combined with oral therapy and achieve variable results, producing cure rates ranging from 20-70\% (Roberts et al. 2003; Marty et al. 2005). Griseofulvin is an antifungal that has been used since 1959 for tinea capitis, and although it is not efficient in nail treatment, it is used for this purpose (Mock et al. 1998; Niewerth \& Korting 2000). Gupta \& Shear (2000), in an excellent review, discussed the percentage cure obtained by different investigators with these drugs using different treatments in patients with toenail onychomycosis.

The aim of our work was to compare the MIC values of five oral antifungals (fluconazole, ketoconazole, itraconazole, terbinafine and griseofulvin) using two methodologies (document M38-A from CLSI and document used by AFST-EUCAST). One hundred samples of Trichophyton spp. (50 strains of T. mentagrophytes and 50 strains of T. rubrum), isolated from adult nails were tested. The following modifications were introduced in the protocols: RPMI-1640 media was supplemented with $2 \%$ glucose at $\mathrm{pH} 7.0$, buffered with MOPS $0.165 \mathrm{M}$, incubation period of $7 \mathrm{~d}$, and temperature of $28^{\circ} \mathrm{C}$, endpoints for fluconazole, itraconazole, ketoconazole and griseofulvin were set at $80 \%$ growth inhibition and $100 \%$ growth inhibition for terbinafine.

\section{Materials and methods}

\section{Isolates}

One hundred strains of Trichophyton mentagrophytes (50 strains) and T. rubrum (50 strains) isolated from different patients diagnosed with onchomycosis, were examined in this study. The clinical mycology laboratory, Mycoses Ltda., Belo Horizonte, Minas Gerais, Brazil, kindly donated these strains. Quality control isolates included T. mentagrophytes (ATCC 40004), T. rubrum (ATCC 40051), Candida parapsilosis (ATCC 22019), and Candida krusei (ATCC 6258). Isolates were cultured on Mycosel ${ }^{\mathrm{TM}}$ (Difco, Sparks, USA) for identification. The isolates were plated on Sabouraud dextrose agar (Difco) at $28^{\circ} \mathrm{C}$ and maintained as a suspension in sterile distilled water (Gupta \& Kohli 2003) at $4{ }^{\circ} \mathrm{C}$ (Pujol et al. 1996) until use.

\section{Medium}

Tests were performed in RPMI 1640 with L-glutamine, but without bicarbonate (Gibco BRL, Life technologies, Woerden,
The Netherlands), pH 7.0, supplemented with $2 \%$ glucose, buffered with MOPS (FisherBiotech, New Jersey). The medium was sterilized by filtration.

\section{Antifungal agents}

Three azole derivatives were used in this study: fluconazole (Pfizer São Paulo, Brazil), ketoconazole and itraconazole (Janssen-Cilag, São José dos Campos, São Paulo, Brazil). The allylamine terbinafine was obtained from Novartis (São Paulo, Brazil) and griseofulvin from Schering-Plough (Rio de Janeiro, Brazil). All drugs were dissolved in $100 \%$ dimethylsulfoxide (DMSO) (Gibco, Belo Horizonte, Minas Gerais, Brazil) following the CLSI protocol and were prepared as stock solutions of $1 \mathrm{mg} \mathrm{ml}^{-1}$. Serial two-fold dilutions were prepared according to document (M38-A) from the CLSI at 100 times the final concentration required, followed by further dilution (1:50) in RPMI 1640 to yield twice the final strength required for the test. The highest concentration of DMSO used in the tests corresponded to $1 \%$ of the total volume and did not interfere with the growth of Trichophyton spp. studied.

\section{Inocula preparation}

Stock suspensions of dermatophytes were prepared from sporulating 7-d-old cultures grown on potato dextrose agar (Acumedia, Baltimore, USA) with $2 \%$ in-house rice flour (Heinlaid et al. 2003; Jessup et al. 2000) at $28^{\circ} \mathrm{C}$. Colonies were covered with $5 \mathrm{ml}$ sterile distilled water and the surface scraped with a sterile loop. The mixture of conidia and hyphal fragments was filtered (Sartorius AG, Goettingen) through an $8 \mu \mathrm{m}$ (Whatman 40, São Paulo, Brazil) sterile filter and collected in a sterile tube. This procedure removed the majority of the hyphae, producing inocula composed mainly of spores (Petrikkou et al. 2001; Santos \& Hamdan 2005; Santos et al. 2006). Turbidity of the final inocula was adjusted to $0.5 \times 10^{6}-5.0 \times 10^{6}$ spores $\mathrm{ml}^{-1}$, at a wavelength of $520 \mathrm{~nm}$, and transmission adjusted to $70 \%$ in a spectrophotometer (Micronal B542, São Paulo). Quantification was made by plating $0.01 \mathrm{ml}$ of a 1:100 dilution of the adjusted inocula (varying between 0.5 to $2.5 \times 10^{6} \mathrm{CFU} \mathrm{ml}^{-1}$ ) on Sabouraud dextrose agar plates. Plates were incubated at $28^{\circ} \mathrm{C}$ and observed daily. Colonies were counted as soon as growth became visible. All inocula were adjusted to a final dilution recommended by both methodologies, in RPMI-1640 supplemented with $2 \%$ glucose.

\section{Test procedure}

Tests were performed in sterile 96-well flat bottom polystyrene plates; $100 \mu$ l of each drug (in two-fold dilutions) were added to the plates that were then stored at $-70 \mathrm{C}$ until use. For the tests, $100 \mu$ l of diluted cell suspension was added to each well so that the final concentration was $0.5 \times 10^{4}-5 \times 10^{4}$ spores $\mathrm{ml}^{-1}$ for protocol M38-A (CLSI) and $0.5 \times 10^{5}-5 \times 10^{5}$ spores $\mathrm{ml}^{-1}$ for protocol AFST-EUCAST. For fluconazole, the concentrations were $64-0.125 \mu \mathrm{g} \mathrm{ml}^{-1}$, for ketoconazole and griseofulvin 8-0.015 $\mu \mathrm{g} \mathrm{ml}^{-1}$, for itraconazole $4-0.007 \mu \mathrm{g} \mathrm{ml}^{-1}$ and for terbinafine 4-0.007 $\mu \mathrm{g} \mathrm{ml}^{-1}$. Control wells (growth and sterility) were included for each assay performed alongside a duplicate series of drug dilutions. After $7 \mathrm{~d}$ at $28^{\circ} \mathrm{C}$, plates were read 
visually (CLSI method) or with a spectrophotometer (AFSTEUCAST method). MICs were determined as the lowest concentration of drug that gave approximately $80 \%$ inhibition (Ghannoum et al. 2004) of the growth control for fluconazole, ketoconazole, itraconazole and griseofulvin. For terbinafine, MICs were the lowest drug concentration that showed $100 \%$ growth inhibition.

\section{Data analysis}

Determination of all MICs was repeated twice. Statistical analyses were performed with Wilcoxon (Mann-Whitney) and Kruskal-Wallis tests. $\mathrm{P}<0.05$ was considered significant.

\section{Results}

MIC values for 100 isolates of Trichophyton spp. are summarized in Tables 1 and 2. Itraconazole and terbinafine had the highest inhibitory activities with both methodologies; $90 \%$ of the isolates had MIC values of $0.25 \mu \mathrm{g} \mathrm{ml}^{-1}$ and $0.015 \mu \mathrm{g} \mathrm{ml}^{-1}$, respectively (Table 2). When the EUCAST method was used, seven isolates of T. mentagrophytes had MICs of $0.5 \mu \mathrm{g} \mathrm{ml}^{-1}$ for itraconazole and one had an MIC of $0.031 \mu \mathrm{g} \mathrm{ml}^{-1}$ for terbinafine (Table 1).

For the drugs ketoconazole and griseofulvin, the $\mathrm{MIC}_{90}$ values were the same using either methodology $\left(1 \mu \mathrm{g} \mathrm{ml}^{-1}\right.$; Table 2). Using the AFST-EUCAST method, one sample of T. mentagrophytes had a MIC of $4 \mu \mathrm{g} \mathrm{ml}^{-1}$ for griseofulvin and none of the T. rubrum isolates had MICs less than $0.5 \mu \mathrm{g} \mathrm{ml}^{-1}$. The same method detected five samples of $T$. mentagrophytes and 13 of T. rubrum with MICs of $2 \mu \mathrm{g} \mathrm{ml}^{-1}$ for the same drug (Table 2).

Fluconazole was the drug with the lowest activity against the isolates. Using both methods the same $\mathrm{MIC}_{50}$ and $\mathrm{MIC}_{90}$ values were observed (Table 2). None of the T. mentagrophytes isolates were susceptible to $4 \mu \mathrm{g} \mathrm{ml}^{-1}$, nevertheless five samples of T. rubrum were susceptible to $\leq 4 \mu \mathrm{g} \mathrm{ml}^{-1}$ when protocols M38-A of CLSI were used and eight samples of T. mentagrophytes had MICs $\geq 64 \mu \mathrm{g} \mathrm{ml}^{-1}$ when the AFSTEUCAST protocol was used (Table 1).

\begin{tabular}{|c|c|c|c|c|c|}
\hline \multirow{2}{*}{$\begin{array}{l}\text { Antifungal } \\
\text { drugs }\end{array}$} & \multirow{2}{*}{$\begin{array}{l}\text { Minimum inhibitory } \\
\text { concentration }\left(\mu \mathrm{g} \mathrm{m}^{-1}\right)\end{array}$} & \multicolumn{2}{|c|}{ Trichophyton mentagrophytes $(n=50)^{c}$} & \multicolumn{2}{|c|}{ Trichophyton rubrum $(n=50)^{c}$} \\
\hline & & $\mathrm{CLSI}^{\mathrm{a}}$ & EUCAST $^{b}$ & CLSI & EUCAST \\
\hline \multirow[t]{8}{*}{ Fluconazole } & $>64$ & 0 & 8 & 0 & 0 \\
\hline & 64 & 7 & 14 & 1 & 21 \\
\hline & 32 & 32 & 19 & 12 & 20 \\
\hline & 16 & 8 & 8 & 27 & 8 \\
\hline & 8 & 3 & 1 & 5 & 1 \\
\hline & 4 & 0 & 0 & 3 & 0 \\
\hline & 2 & 0 & 0 & 1 & 0 \\
\hline & 1 & 0 & 0 & 1 & 0 \\
\hline \multirow[t]{6}{*}{ Ketoconazole } & 2 & 2 & 2 & 0 & 3 \\
\hline & 1 & 8 & 8 & 4 & 19 \\
\hline & 0.5 & 16 & 31 & 10 & 18 \\
\hline & 0.25 & 18 & 5 & 28 & 7 \\
\hline & 0.125 & 5 & 3 & 5 & 2 \\
\hline & 0.062 & 1 & 1 & 3 & 1 \\
\hline \multirow[t]{6}{*}{ Itraconazole } & 0.5 & 0 & 7 & 0 & 0 \\
\hline & 0.25 & 4 & 14 & 7 & 32 \\
\hline & 0.125 & 20 & 27 & 15 & 17 \\
\hline & 0.062 & 15 & 2 & 14 & 1 \\
\hline & 0.031 & 4 & 0 & 14 & 0 \\
\hline & 0.015 & 7 & 0 & 0 & 0 \\
\hline \multirow[t]{7}{*}{ Griseofulvin } & 4 & 0 & 1 & 0 & 0 \\
\hline & 2 & 0 & 5 & 0 & 13 \\
\hline & 1 & 3 & 8 & 9 & 25 \\
\hline & 0.5 & 10 & 33 & 12 & 12 \\
\hline & 0.25 & 16 & 3 & 24 & 0 \\
\hline & 0.125 & 21 & 0 & 4 & 0 \\
\hline & 0.062 & 0 & 0 & 1 & 0 \\
\hline \multirow[t]{4}{*}{ Terbinafine } & 0.031 & 0 & 1 & 3 & 1 \\
\hline & 0.015 & 22 & 11 & 0 & 16 \\
\hline & 0.007 & 13 & 9 & 14 & 33 \\
\hline & $<0.007$ & 15 & 29 & 33 & 0 \\
\hline
\end{tabular}


Table 2 - MICs of five drugs against Trichophyton species assessed by National Committee for Clinical Laboratory Standards (CLSI)/European Committee on Antimicrobial Susceptibility Testing (EUCAST) methods

\begin{tabular}{|c|c|c|c|c|}
\hline \multirow[t]{2}{*}{ Antifungal drugs } & \multicolumn{2}{|c|}{$\mathrm{MIC}_{50}\left(\mu \mathrm{g} \mathrm{ml}^{-1}\right)^{\mathrm{a}}$} & \multicolumn{2}{|c|}{$\mathrm{MIC}_{90}\left(\mu \mathrm{g} \mathrm{ml}^{-1}\right)^{\mathrm{a}}$} \\
\hline & NCCLS $^{b}$ & EUCAST $^{\mathrm{C}}$ & NCCLS & EUCAST \\
\hline Fluconazole & 32 & 64 & 32 & 64 \\
\hline Ketoconazole & 0.25 & 0.5 & 1 & 1 \\
\hline Itraconazole & 0.125 & 0.25 & 0.25 & 0.25 \\
\hline Griseofulvin & 0.25 & 0.5 & 1 & 1 \\
\hline Terbinafine & 0.007 & 0.007 & 0.015 & 0.015 \\
\hline \multicolumn{5}{|c|}{$\begin{array}{l}\text { a - MICs at which } 50 \% \text { and } 90 \% \text { of the isolates tested were in- } \\
\text { hibited, respectively. } \\
\text { b Document M38-A (2002). } \\
\text { c Document AFST-EUCAST (2002). }\end{array}$} \\
\hline
\end{tabular}

For all drugs tested, both methodologies gave similar $\mathrm{MIC}_{50}$ values (Table 2). Table 3 shows that more than $92 \%$ of the strains varied by less than three dilutions in both methods (CLSI and EUCAST). There was no significant difference $(P<0.05)$ between MIC values of both tested species with the two tested methods, considering no dilution interval.

\section{Discussion}

Currently, there are published data comparing the in vitro susceptibility of yeasts, especially Candida spp., using documents CLSI M27-A2, AFST-EUCAST and E-test (Chryssanthou \& Cuenca-Estrella 2002; Cuenca-Estrella et al. 2002, 2005; Romero et al. 2004), but there is a scarcity of studies including dermatophytic fungi. In this study we compared two methods of microdilution in liquid media to determine the susceptibility of dermatophytes to antifungal drugs. Five drugs currently used in the treatment of dermatophytosis were tested (Mukherjee et al. 2003).

Korting et al. (1995) using the method described by Granade \& Artis (1980), reported an MIC 90 for griseofulvin of $10 \mu \mathrm{g} \mathrm{ml}^{-1}$ for T. mentagrophytes isolates and of $3 \mu \mathrm{g} \mathrm{ml}^{-1}$ for T. rubrum. Here, we observed using both protocols (M38-A of CLSI and AFST-EUCAST) lower MIC $_{90}$ values of $1 \mu \mathrm{g} \mathrm{ml}^{-1}$, for both species (Table 2). They also obtained very high MIC values for fluconazole $\left(1024 \mu \mathrm{g} \mathrm{ml}^{-1}\right)$. In this study values obtained for fluconazole were MIC $\geq 64 \mu \mathrm{g} \mathrm{ml}^{-1}$. An $\mathrm{MIC}_{90}$ of $2 \mu \mathrm{g} \mathrm{ml}^{-1}$ was found for fluconazole against dermatophytes by both Jessup et al. (2000) and Ghannoum et al. (2004), which is very different from the MIC found in the present study $\left(\mathrm{MIC}_{90}=32 \mu \mathrm{g} \mathrm{ml}^{-1}\right)$. This is possibly due to differences in the incubation period. In the case of terbinafine, very low values were observed by Korting et al. (MIC $\left.=0.05 \mu \mathrm{g} \mathrm{ml}^{-1}\right)$ and similar results were obtained in our study $\left(0.015 \mu \mathrm{g} \mathrm{ml}^{-1}\right)$.

Our data, by using both methods, were similar to the ones obtained by Fernández-Torres et al. (2000), Fernández-Torres et al. (2001) and Serrano-Martino et al. (2003). MIC 50 values for ketoconazole and itraconazole varied by just for one dilution (plus or minus), while for terbinafine both methods were the same.

Gupta \& Kohli (2003), working with 68 samples of T. rubrum and 14 of T. mentagrophytes and method M27-A (CLSI), found
Table 3 - Agreement of the National Committee for Clinical Laboratory Standards (CLSI) and the European Committee on Antimicrobial Susceptibility Testing (EUCAST) methods at the same dilutions for 100 isolates of Trichophyton species

\begin{tabular}{|c|c|c|c|c|c|}
\hline \multirow[t]{2}{*}{ Drugs } & \multirow[t]{2}{*}{ Dilutions $^{a}$} & \multicolumn{2}{|c|}{$\begin{array}{l}\text { Trichophyton } \\
\text { mentagrophytes }\end{array}$} & \multicolumn{2}{|c|}{$\begin{array}{c}\text { Trichophyton } \\
\text { rubrum }\end{array}$} \\
\hline & & $n=50^{b}$ & $\%^{c}$ & $n=50$ & $\%$ \\
\hline \multirow[t]{7}{*}{ Fluconazole } & 0 & 15 & 30 & 16 & 32 \\
\hline & 1 & 22 & 44 & 14 & 28 \\
\hline & 2 & 9 & 18 & 13 & 26 \\
\hline & 3 & 3 & 6 & 4 & 8 \\
\hline & 4 & 1 & 2 & 1 & 2 \\
\hline & 5 & 0 & 0 & 1 & 2 \\
\hline & 6 & 0 & 0 & 1 & 2 \\
\hline \multirow[t]{5}{*}{ Ketoconazole } & 0 & 18 & 36 & 7 & 14 \\
\hline & 1 & 24 & 48 & 17 & 34 \\
\hline & 2 & 4 & 8 & 19 & 38 \\
\hline & 3 & 3 & 6 & 5 & 10 \\
\hline & 4 & 1 & 2 & 2 & 4 \\
\hline \multirow[t]{6}{*}{ Itraconazole } & 0 & 11 & 22 & 12 & 24 \\
\hline & 1 & 20 & 40 & 14 & 28 \\
\hline & 2 & 9 & 18 & 16 & 32 \\
\hline & 3 & 6 & 12 & 8 & 16 \\
\hline & 4 & 2 & 4 & 0 & 0 \\
\hline & 5 & 2 & 4 & 0 & 0 \\
\hline \multirow[t]{6}{*}{ Griseofulvin } & 0 & 9 & 18 & 8 & 16 \\
\hline & 1 & 18 & 36 & 14 & 28 \\
\hline & 2 & 16 & 32 & 16 & 32 \\
\hline & 3 & 4 & 8 & 12 & 24 \\
\hline & 4 & 2 & 4 & 0 & 0 \\
\hline & 5 & 1 & 2 & 0 & 0 \\
\hline \multirow[t]{3}{*}{ Terbinafine } & 0 & 12 & 24 & 5 & 10 \\
\hline & 1 & 21 & 42 & 31 & 32 \\
\hline & 2 & 17 & 34 & 14 & 28 \\
\hline
\end{tabular}

a 0 - at same dilution; 1, 2, 3, 4, 5, 6- number of dilutions for up or down, between CLSI and EUCAST methods.

b Number of isolates.

c Percentage in agreement.

the $\mathrm{MICs}_{90}$ for ketoconazole, itraconazole and terbinafine very similar to the ones reported here. Using a different method, and other species of dermatophytes such as Epidermophyton floccosum, Microsporum canis and Microsporum gypseum, Favre et al. (2003) also found the $\mathrm{MIC}_{90}$ for fluconazole similar to the ones reported here, leading us to conclude that fluconazole should not chosen for the treatment of dermatophyte infections.

Overall, our data demonstrate the reproducibility of the methods employed to perform susceptibility tests in dermatophytes and confirm the in vitro inefficacy of fluconazole, as well as the excellent antifungal activity of terbinafine, and good activity of itraconazole. The methods suggested by the CLSI (document M38-A) and by the AFST-EUCAST can be considered very good protocols to determine MIC values in dermatophytes. Our modifications to adapt the susceptibility tests to this group of fungi did not affect the accuracy of the techniques when applied to this specific group. Moreover, the results we have obtained provide greater reproducibility and reliability of susceptibility/resistance 
determination than previous methods. In the future, we hope that standardization of these methodologies will allow clinical-laboratory studies to better correlate MIC values with clinical outcomes.

\section{Acknowledgements}

We are grateful to Walquíria Lopes Borges, Bernardo Drumond Matias, and Tânia Mara de Gomes Pinho for excellent technical assistance.

\section{R E F E R E N C E S}

AFST-EUCAST, 2002. Reference Method for Determination of Minimal Inhibitory Concentration (MIC) by Broth Dilution of Fermentative Yeasts. Discussion document E. Dis. 7.1 ESCAMID. Subcommittee of Antifungal Susceptibility Testing of the European Committee on Antibiotic Susceptibility Testing of the European Society of Clinical Microbiology and Infectious Diseases. Taufkirchen.

Bradley MC, Leidich S, Isham N, Elewski BE, Ghannoum MA, 1999. Antifungal susceptibilities and genetic relatedness of serial Trichophyton rubrum isolates from patients with onychomycosis of the toenail. Mycoses 42: 105-110.

Chryssanthou E, Cuenca-Estrella M, 2002. Comparison of the antifungal susceptibility testing subcommittee of the European committee on antibiotic susceptibility testing proposed standard and E-test with the CLSI broth microdilution method for voriconazole and caspofungin susceptibility testing of yeast species. Journal of Clinical Microbiology 40: 3841-3844.

CLSI (NCCLS), 2002a. Reference Method for Broth Dilution Antifungal Susceptibility Testing of Yeast; Approved Standard document M27A2, 2nd edn. National Committee for Clinical Laboratory Standards, Wayne, PA.

CLSI (NCCLS), 2002b. Reference Method for Broth Dilution Antifungal Susceptibility Testing of Filamentous Fungi; Approved Standard document M38-A. National Committee for Clinical Laboratory Standards, Wayne, PA.

Cuenca-Estrella M, Gomez-Lopez A, Mellado E, RodriguezTudela JL, 2005. Correlation between the procedure for antifungal susceptibility testing for Candida spp. of the european committee on antifungal susceptibility testing (EUCAST) and four commercial techniques. Clinical Microbiology and Infection 11: 486-492.

Cuenca-Estrella M, Lee-Yang W, Ciblak MA, ArthingtonSkaggs BA, Mellado E, Warnak OW, Rodriguez-Tudela JL, 2002. Comparative evaluation of CLSI M27-A and EUCAST broth microdilution procedures for antifungal susceptibility testing of Candida species. Antimicrobial Agents and Chemotherapy 46: 3644-3647.

Cuenca-Estrella M, Moore CB, Barchiese F, Bille J, Chryssanthou E, Denning DW, Donnelly JP, Dromer F, Dupont B, Rex JH, Richardson MD, Sancak B, Verweij PE, Rodriguez-Tudela JL, AFST Subcommittee of the European Committee on Antimicrobial Susceptibility Testing, 2003. Multicenter evaluation of the reproducibility of the proposed antifungal susceptibility testing method for fermentative yeasts of the Antifungal Susceptibility Testing Subcommittee of the European Committee on Antimicrobial Susceptibility Testing (AFST-EUCAST). Clinical Microbiology and Infection 9: 467-474.

Favre B, Hofbauer B, Hildering KS, Ryder NS, 2003. Comparisson of in vitro activities of 17 antifungal drugs against a panel of 20 dermatophytes by using a microdilution. Journal of Clinical Microbiology 41: 4817-4819.

Fernández-Torres B, Vázquez-Veiga H, Llovo X, Pereiro Jr M, Guarro J, 2000. In vitro susceptibility to itraconazole, clotrimazole, ketoconazole and terbinafine of 100 isolates of Trichophyton rubrum. Chemotherapy 46: 390-394.

Fernández-Torres B, Carrillo AJ, Martín E, Del Palacio A, Moore MK, Valverde A, Serrano M, Guarro J, 2001. In vitro activities of ten antifungal drugs against 508 dermatophyte strains. Antimicrobial Agents and Chemotherapy 45: 2524-2528.

Ghannoum MA, Chatuverdi V, Espinel-Ingroff A, Pfaller MA, Rinaldi MG, Lee-Yang W, Warnock DW, 2004. Intra- and interlaboratory study of a method for testing the antifungal susceptibilities of dermatophytes. Journal of Clinical Microbiology 42: 2977-2979.

Granade TC, Artis WM, 1980. Antimycotic susceptibility testing of dermatophytes in microcultures with a standardized fragmented mycelial inoculum. Antimicrobial Agents and Chemotherapy 17: 725-729.

Gupta AK, Kohli Y, 2003. In vitro susceptibility testing of ciclopirox, terbinafine, ketoconazole and itraconazole against dermatophytes and nondermatophytes, and in vitro evalution of combination antifungal activity. British Journal of Dermatology 149: 296-305.

Gupta AK, Shear NH, 2000. A risk-benefit assessment of the newer oral antifungal agents used to treat onychomycosis. Drugs Safety 22: 33-52.

Heinlaid K, Naaber P, Jarv H, 2003. Evaluation of media to enhance conidial production of dermatophytes. Clinical Microbiology and Infection 9: 335.

Jessup CJ, Warner J, Isham N, Hasan I, Ghannoum MA, 2000. Antifungal susceptibility testing of dermatophytes: establishing a medium for inducing conidial growth and evaluation of susceptibility of clinical isolates. Journal of Clinical Microbiology 38: 341-344.

Korting HC, Ollert M, Abeck D, German Collaborative Dermatophyte Drug Susceptibility Study Group, 1995. Results of german multicenter study of antimicrobial susceptibilities of Trichophyton rubrum and Trichophyton mentagrophytes strains causing tinea unguium. Antimicrobial Agents and Chemotherapy 39: $1206-1208$.

Marty JP, Lambert J, Jackel A, Adjadj L, 2005. Treatment costs of three nail lacquers used in onychomycosis. Journal of Dermatological Treatment 16: 299-307.

Meletiadis J, Mouton JW, Meis JFGM, Bouman BA, Verweij PE, EUROFUNG N, 2002. Comparison of the Etest and Sensititre colorimetric methods with the NCCLS proposed standard for antifungal susceptibility testing of Aspergillus species. Journal of Clinical Microbiology 40: 2876-2885.

Mock M, Monod M, Baudraz-Rosselet F, Panizzon RG, 1998. Tinea capitis dermatophytes: susceptibility to antifungal drugs tested in vitro and in vivo. Dermatology 197: 361-367.

Mukherjee PK, Leidich SD, Isham N, Leitner I, Ryder NS, Ghannoum MA, 2003. Clinical Trichophyton rubrum strain exhibiting primary resistance to terbinafine. Antimicrobial Agents and Chemotherapy 47: 82-86.

Niewerth M, Korting HC, 2000. The use of systemic antimycotics in dermatotherapy. European Journal of Dermatology 10: 155-160.

Petrikkou E, Rodríguez-Tudela JL, Cuenca-Estrella M, Gómez A, Molleja A, Mellado E, 2001. Inoculum standardization for antifungal susceptibility testing of filamentous fungi pathogenic for humans. Journal of Clinical Microbiology 39: 1345-1347.

Pujol I, Guarro J, Llop C, Soler L, Fernández-Ballart J, 1996. Comparison study of broth macrodilution and microdilution antifungal susceptibility tests for the filamentous fungi. Antimicrobial Agents and Chemotherapy 40: 2106-2110.

Roberts DT, Taylor WD, Boyle J, 2003. Guidelines for treatment of onychomycosis. British Journal of Dermatology 148: 402-410. 
Romero M, Cánton E, Péman J, Gobernado M, 2004. Estudio de la actividad in vitro de caspofungin sobre especies de levaduras diferentes de Candida albicans, determinada por dos métodos: M27-A2 y EUCAST. Revista Española de Quimioterapia 17: 257-262.

Santos DA, Hamdan JS, 2005. Evaluation of broth microdilution antifungal susceptibility testing conditions for Trichophyton rubrum. Journal of Clinical Microbiology 43: 1917-1920.
Santos DA, Barros MES, Hamdan JS, 2006. Establishing a method of inoculum preparation for susceptibility testing of Trichophyton rubrum and Trichophyton mentagrophytes. Journal of Clinical Microbiology 44: 98-101.

Serrano-Martino MC, Chávez-Caballero M, Valverde-Conde A, Clar RM, Peman J, Martin-Mazuelos E, 2003. Actividad in vitro de voriconazol y otros tres antifúngicos frente a dermatofitos. Enfermedades Infecciosas y Microbiología Clínica 21: 484-487. 